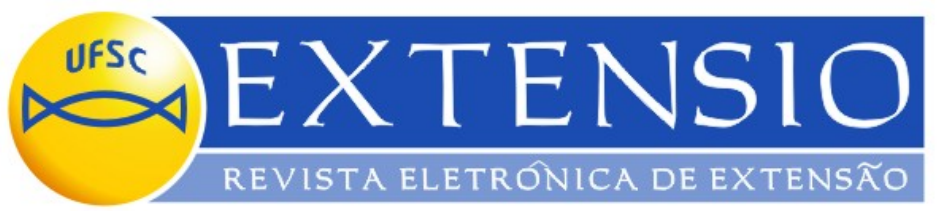

\title{
GRUPO DE GESTANTES E/OU CASAIS GRÁVIDOS E A INSERÇÃO DO ACOMPANHANTE/PAI NO PROCESSO DE NASCIMENTO
}

\author{
Jerusa Mendes Junckes, Joice Cristina Guesser \\ Acadêmicas do Curso de Enfermagem da UFSC \\ Dra. Maria de Fátima Mota Zampieri \\ Professora do Departamento de Enfermagem da UFSC (Coordenadora) \\ mfatima@nfr.ufsc.br \\ Vitória Regina Peters Gregório \\ Professora Assistente do Departamento de Enfermagem da UFSC \\ Zaira Custódio de Oliveira \\ Psicóloga do Hospital Universitário da UFSC \\ Isabel Regis \\ Socióloga e professora aposentada da UFSC
}

\section{Resumo}

Estudo qualitativo, descritivo e exploratório que aborda a importância do grupo de Gestantes e/ou Casais Grávidos na inserção do acompanhante/pai no processo de nascimento. Os dados foram levantados com base nos depoimentos dos participantes desse grupo. Verificou-se a contribuição da mesma atividade para inclusão do pai no processo de nascimento e para o exercício e fortalecimento da paternidade.

Palavras-chave: Acompanhante/pai. Grupo de gestantes. Processo de nascimento.

\section{GROUP OF PREGNANT WOMEN AND/OR PREGNANT COUPLES AND THE PARTNER/FATHER INSERTION IN THE BIRTH PROCESS}

\begin{abstract}
Qualitative, descriptive and exploratory study that approaches the importance of the group of Pregnant Women and/or Pregnant Couples in the insertion of the partner/father in the birth process. The data were collected based on declarations of the participants of this group. The contribution of the same activity for the father inclusion in the birth process and for the paternity exercise and consolidation (invigoration) was verified.
\end{abstract}

Keywords: Partner/father. Pregnant women. Birth process. 


\section{Introdução}

A gestação é um processo transicional, complexo, único, especial e multidimensional que envolve a mulher, o homem, a família e a sociedade. Não se trata apenas de um evento isolado nem descontextualizado dos demais processos que ocorrem na vida humana. Ela é influenciada pelas experiências anteriores dos envolvidos, por suas crenças, valores, cultura e educação e pelo contexto existencial, assistencial e socioeconômico em que ocorre (ZAMPIERI, 2006b).

Segundo Sartori e Van Der Sand (2004) e Maldonado (2005), a gravidez é um período de constantes modificações físicas, psicológicas e sociais na vida da mulher grávida e de todos que participam do processo de nascimento ${ }^{1}$, em especial, do companheiro e futuro pai. É um período de transição, de mudanças de identidade e de papéis sociais, em que são necessárias novas adaptações, reajustamentos interpessoais e intrapsíquicos.

Para Noronha, Lopes e Montgomery (1993), a experiência de ter um filho inaugura um momento importante no ciclo vital da mulher, do homem e dos familiares. A grávida, além de mulher e filha, passa a ser mãe, e o homem, além de filho e companheiro, passa a ser pai. Surge uma nova mulher, um novo ser, um novo pai e uma nova família (MALDONADO, 2005).

A mulher e o homem passam a se comprometer e a se responsabilizar pela vida e bem estar de uma nova pessoa que vai nascer; situam-se como pai e mãe e apresentam novas expectativas, sensações, dúvidas e medos, típicos e singulares da gestação, do parto e do pósparto (MALDONADO; DICKSTEIN; NAHOUM, 2000).

No processo gestacional, a maternidade pode se constituir numa situação de crise para a mulher em função das intensas transformações oriundas da gravidez e definição de novos papéis na sociedade. Da mesma forma, a paternidade pode ser uma situação crítica no desenvolvimento emocional do homem. O medo, as incertezas, o impacto diante das mudanças e a responsabilidade de ter que assumir o bebê levam o homem a viver um momento conflituoso e ambíguo (FREITAS; COELHO; SILVA, 2007).

Dado o momento de transformação e de reestruturação pessoal e familiar, de amadurecimento do homem e da mulher, do relacionamento, da triangulação e formação do trinômio mãe-filho-pai, a gravidez é um período do desenvolvimento humano que possibilita grande aprendizado, tornando-se uma ótima oportunidade para os profissionais da equipe de saúde desenvolverem a educação como dimensão do processo de cuidar (TIBA, 2002; RIOS;

\footnotetext{
${ }^{1}$ É compreendido desde a pré-concepção até o puerpério (OLIVEIRA; ZAMPIERI; BRUGGEMANN, 2001).
} 
VIEIRA, 2007).

Para Alonso e Verdi (2005), o componente educativo acompanha diretamente o processo de cuidar. Assim, o processo educativo está presente intrinsecamente nos cuidados de enfermagem: enquanto o enfermeiro cuida, educa; enquanto educa, cuida. Uma das estratégias para educar é o desenvolvimento de atividades grupais. O trabalho educativo em grupo oportuniza a participação dos indivíduos, amplia a possibilidade de as pessoas se autoconhecerem e diversificarem mais suas relações (SAID, 1995). Propicia ainda aos envolvidos se aproximarem e criarem laços de amizade; compartilharem vivências que são comuns, criando um clima de compreensão e entendimento, o que pode facilitar a compreensão de seus problemas e até minimizá-los. Ademais, possibilita o compartilhamento de alegrias, tristezas, medos, dores, saberes e experiências. A dinâmica grupal fortalece as potencialidades individuais e coletivas, amplia a visão dos recursos disponíveis para as ações de saúde e encoraja os indivíduos e grupos a buscarem novas estratégias para enfrentar os desafios (ALONSO; VERDI, 2005; SAID, 1995).

As atividades grupais com gestantes e seus acompanhantes ${ }^{2}$ criam oportunidades para a troca de conhecimentos e experiências, expressão de sentimentos, medos e dúvidas que surgem no cotidiano da mulher, contribuindo para melhor adaptação a nova fase. Para Sartori e Van Der Sand (2004), o grupo de gestantes tem um poder terapêutico, já que, no jogo dos iguais e das interações, as pessoas podem reelaborar seus sentimentos em relação ao momento vivido, enfrentar situações de crise, ressignificar suas vivências, através do reconhecimento dos outros e de si. Na convivência grupal, há possibilidade de geração de conhecimentos, troca de vivências e de narrativas. Segundo Alves (2004), com a verbalização das situações ocorridas em suas vidas, os envolvidos no processo de nascimento podem superar suas meras narrativas, aprendendo ainda mais com as experiências e, assim, capacitarem-se para atuar de forma criativa, superar dificuldades e reinventar a vida cotidiana, a partir das trocas e da participação crítica. Dessa forma, o grupo de gestantes ajuda a consolidar a capacidade da mulher e de seu companheiro de acolher e cuidar paternalmente e maternalmente do filho que vai nascer.

Buscando favorecer a mulher e a família, a vivência saudável e tranquila do processo de nascimento, é realizada, desde 1996, no Hospital Universitário da Universidade Federal de Santa Catarina, a atividade de extensão intitulada Grupo de Gestantes e/ou Casais Grávidos,

\footnotetext{
${ }^{2}$ Pessoas de referência da gestante que dão suporte emocional e conforto físico à gestante. Podem ser profissionais (enfermeira, parteira), companheiro/familiar ou amiga da parturiente, doula e mulher leiga designada para tal função durante o trabalho de parto (BRÜGGEMANN; PARPINELLI; OSIS, 2005).
} 
dirigida às gestantes e acompanhantes atendidos na rede pública ou privada. Tal atividade educativa e interdisciplinar tem, como coordenadores, professores do Departamento de Enfermagem, psicóloga da maternidade do HU e socióloga aposentada da UFSC, e conta com a participação de casais grávidos, gestantes, acompanhantes, acadêmicos e bolsistas de enfermagem e de psicologia. A atividade é guiada por pressupostos da filosofia da maternidade do referido hospital, os quais têm, como eixos principais, a humanização do cuidado, a autonomia da clientela, interdisciplinaridade e princípios ligados à promoção da saúde.

O objetivo geral da atividade educativa, segundo Santos, Zampieri e Custódio (1996), é prestar um atendimento interdisciplinar, de prevenção primária, às gestantes e/ou casais grávidos do terceiro ao oitavo mês de gestação. Segundo Zampieri (2007), busca-se: desenvolver uma tomada de consciência corporal e postural; orientar técnicas de respiração e de relaxamento; orientar e compartilhar conhecimentos e experiências sobre o ciclo grávidopuerperal; permitir a expressão de vivências emocionais, medos e dúvidas em relação ao processo de nascimento e novos papéis assumidos pela gestante, companheiro e família; oportunizar a troca de experiências entre os participantes; promover a visita à maternidade do HU e informar sobre suas rotinas; oportunizar a participação de profissionais de outras instituições; realizar atividades de ensino e pesquisa e realizar encontro de pais e bebês.

Os encontros são realizados semanalmente, nas quintas-feiras, no horário das $14 \mathrm{~h}$ às 18h, no prédio de capacitação do HU, durante um período de oito semanas consecutivas. Essa atividade é divulgada por meio de cartazes e pelo site da Universidade. Cada encontro é dividido em três momentos: 1) conscientização corporal, técnicas de relaxamento e respiração, que permitem às gestantes e aos acompanhantes aprenderem exercícios, respirar e relaxar; 2) lanche, que facilita o entrosamento entre os participantes; 3) tematização, momento em que se discutem os temas de interesse do grupo, escolhidos por eles no primeiro encontro.

Com base nos momentos descritos anteriormente, o grupo de gestantes e/ou casais grávidos constitui-se num espaço de socialização de conhecimentos e experiências sobre o ciclo grávido-puerperal, visando fortalecer os potenciais da gestante, acompanhantes e familiares, para que possam ter uma participação mais ativa no processo de nascimento e uma vivência mais plena nesta fase de suas vidas (ZAMPIERI, 2006a).

Além disso, tem sido um espaço para estimular a participação do companheiro/pai ou do acompanhante e inseri-lo nas várias etapas do processo de nascimento (ZAMPIERI, 2007). O acompanhante, pessoa de referência da gestante, que faz parte de sua rede de apoio, pode fornecer o suporte emocional, educacional e social, aumentar a autoestima da gestante, dar a 
ela mais segurança, atenção e carinho em todo o processo de nascimento, ou seja, desde a gestação ao pós-parto. A participação do acompanhante durante todo esse processo auxilia a mulher a controlar e reduzir a sensação de dor; contribui para diminuir a duração do trabalho de parto e a utilização de analgesia e oxitocina; reduz significativamente o percentual de cesáreas, favorecendo participação da mulher no trabalho de parto, o que aumenta a sua potencialidade para dar à luz, além de fortalecer os laços afetivos e familiares. Além disso, reduz o tempo de hospitalização dos recém-nascidos.

A participação do homem em todo o processo de nascimento e o surgimento de um novo pai que assume o compromisso social de prover e proteger a família e também se comprometer afetiva e pessoalmente com seu filho e companheira é recente. Nas sociedades ocidentais, ao longo dos anos, os papéis de pais e mães construídos culturalmente e socialmente têm sido tradicionalmente diferentes. A mãe vem assumindo o papel de cuidadora primária e o pai, o encargo socioeconômico de proteger, cuidar e manter os familiares, sendo o provedor das necessidades materiais da família, distanciando-se muitas vezes do convívio familiar (PICCININI et al. 2004). Trindade (1993) lembra que, na família, o menino é menos ou quase nunca inserido nas tarefas domésticas e é considerado como pouco importante nesse tipo de atividade. Por outro lado, o papel materno da menina é supervalorizado, o que transforma o paterno como secundário no processo de transição para a parentalidade ${ }^{3}$.

A trajetória masculina rumo à parentalidade difere da feminina por diversos fatores. Para Piccinini et al. (2004), um deles é que somente a mulher sente o filho crescer em seu ventre, dá à luz e amamenta. Para Ávila (1998), o homem não foi preparado para ser pai, mas sim para ser homem, para o poder e o ter. O homem grávido geralmente se sente confuso, desamparado, inseguro e ansioso frente à gravidez. Sofre por si mesmo, pela sua companheira e pelo filho e não pode ou não consegue expressar tudo o que sente.

Brazelton (1988) adverte que o homem pode se sentir excluído no processo de nascimento. Todos estão preocupados com os sentimentos da futura mãe e esquecem o pai, seus sentimentos e necessidades. A mulher tende a desviar suas energias e atenção para o bebê e se torna o centro das atenções. Não dá espaço para o pai, acreditando que só ela pode cuidar bem do filho. Muitos profissionais de saúde deixam de dar a devida atenção ao pai e não o introduzem no processo desde a gestação. No entanto, o homem precisa fazer adaptações similares às da mulher e também enfrenta dúvidas e angústias semelhantes.

\footnotetext{
${ }^{3}$ Processo complexo de mudança e de transição, social e psicológico, pelo qual o casal, mulher e homem, se tornam mães e pais, progenitores de uma nova família, que inicia já na pré-concepção. Envolve todas as transformações psicológicas, a organização dos papéis e relacionamentos dos pais (COWAN, 1988; MENEZES; LOPEZ, 2007; ANDREANI, 2006).
} 
Por essas razões, de acordo com Maldonado, Dickstein e Nahoum (2000), a formação do vínculo entre pai e filho costuma ser mais lenta, consolidando-se apenas após o nascimento e no decorrer do desenvolvimento da criança. No entanto, isso vem se transformando na medida em que a mulher entra no mercado do trabalho, pois o grande envolvimento das mulheres no campo profissional e o novo papel social do trabalho feminino vêm abrindo espaços para a inclusão dos pais nos cuidados com seus filhos. Têm, aliás, oportunizado aos pais uma participação mais ativa no exercício de sua parentalidade, exercendo influências diretas sobre o desenvolvimento de seus filhos (PARKE, 1996).

Piccinini et al. (2004) aponta que o envolvimento paterno durante a gestação deve ser compreendido de modo peculiar, pois o vínculo entre pai e filho é indireto, mediado pela mãe. Parke (1996) ressalta que os casais, e não apenas as mulheres, ficam grávidos. As mudanças ocorridas com os futuros pais durante a gravidez não são independentes das mudanças pelas quais passam as próprias gestantes. Os pais podem desenvolver a Síndrome de Couvade, apresentando sintomas físicos e psicológicos semelhantes e concomitantes aos das mulheres. Para Perseval (1986) e Maldonado (2005), esse quadro pode ser sinônimo de competição com a gestante, mas também a forma de expressar sentimentos de identificação e empatia com ela. Assim, pode estar relacionado com a participação e o envolvimento emocional que o homem tem com a companheira grávida.

O envolvimento paterno na gestação pode se dar por meio da expressão de suas preocupações e ansiedades, de sua participação na atenção pré-natal (consultas, atividades educativas coletivas e individuais, consultas, visitas domiciliares), no envolvimento com os preparativos para a chegada do bebê, através do apoio emocional proporcionado à mãe e do estabelecimento do vínculo com o bebê (PICCININI et al., 2004).

No intuito de minimizar os dilemas vivenciados tanto pelo pai quanto pela mãe, o Grupo de Gestantes do HU procura facilitar o engajamento do pai e familiares na gravidez. Oferece um espaço de diálogo, de troca de experiências entre os casais grávidos e acompanhantes; estimula a conscientização corporal do casal; aborda assuntos que enfocam a gestação, amamentação, parto, puerpério, cuidados com o recém-nascido $(\mathrm{RN})$ e formação da nova família. Procura, assim, valorizar os sentimentos, dar suporte emocional e respeitar o ritmo, tanto do pai quanto da mãe, na formação da nova família. Fortalece os conhecimentos e potenciais do acompanhante em relação ao processo vivido, estimulando a sua participação, e aumenta sua segurança para dar suporte à mulher na gestação, parto e pós-parto. Assim, o Grupo de Gestantes do HU atende as premissas da Política Nacional de Atenção Obstétrica e Neonatal, portaria $n^{\circ} .1 .067 / G M$ de 4 de julho de 2005, que, entre outras questões, reforça que 
as gestantes têm o direito ao acompanhamento e acesso à atenção pré-natal, à assistência ao parto e pós-parto e o direito ao acompanhante já referendado pela lei $\mathrm{n}^{\circ}$. 11.108/05 de 7 de abril de 2005 (BRASIL, 2005).

Diante do exposto, acredita-se que a troca de saberes e de experiências no grupo de gestantes e/ou casais grávidos suscita o diálogo entre o casal, contribui para que descubram e consolidem seus papéis sociais no processo de nascimento, dá subsídios para que os familiares e acompanhantes possam dar suporte emocional e tranquilidade à gestante.

Apesar dos esforços de profissionais de saúde que lutam por uma assistência humanizada, observamos que a inclusão do pai no processo de nascimento, mesmo com a implementação da política obstétrica e lei do acompanhante, ainda precisa ser conquistada em alguns lugares e sedimentada em outros. Além disso, é reduzido o número de trabalhos nacionais abordando o tema e estudos que expressam a percepção dos agentes sociais que vivenciam o processo. Ademais, nota-se que ainda é pequena a valorização do pai e/ou pessoa de referência da gestante no processo de nascimento.

Com este estudo, buscou-se saber qual a importância de um grupo de gestantes e/ou casais grávidos na inserção do acompanhante e/ou pai no processo de nascimento, na ótica desses atores sociais.

Delinearam-se, neste estudo, os seguintes objetivos: conhecer a percepção de gestantes, companheiros e acompanhantes em relação à contribuição do grupo para a inserção do acompanhante e/ou pai no processo de nascimento e identificar o significado da vivência gestacional na vida dos participantes após o término dos encontros.

\section{Material e Métodos}

Trata-se de uma pesquisa qualitativa, descritiva e exploratória. Busca-se conhecer e destacar a importância do grupo de gestantes e/ou casais grávidos para inserção do acompanhante e o significado desta vivência para estes atores sociais.

A pesquisa qualitativa, segundo Biasoli-Alves (1998), procura apreender os significados, as falas e outros comportamentos dos sujeitos dentro de seu contexto. Esse tipo de pesquisa leva em consideração a sua qualidade e não se propõe a atingir a representatividade. De acordo com Minayo (1999), a pesquisa qualitativa em saúde trabalha com o universo de significados, motivações, aspirações, crenças, valores e atitudes, o que corresponde a um espaço mais profundo das relações, dos processos e dos fenômenos que não podem ser reduzidos à operacionalização de variáveis. 
A população alvo constituiu-se de gestantes e acompanhantes e/ou pai, participantes do grupo de gestantes e/ou casais grávidos realizado no Hospital Universitário.

Com base nos depoimentos dos sujeitos do estudo transcritos ao longo dos 12 anos de existência do grupo, análise documental (avaliações dos grupos e síntese dos encontros de pais e bebês) e respostas do formulário aplicado nos dois últimos grupos de 2007, grupos 45 e 46, contendo o questionamento - "Qual a importância do grupo de gestantes para a participação mais ativa e inserção do acompanhante no processo de nascimento?”- buscamos compreender a importância e contribuição do grupo de gestantes para a inclusão e inserção da pessoa da escolha da gestante neste novo processo do desenvolvimento da vida humana. Os dados qualitativos coletados foram sistematicamente organizados e descritos de acordo com Bardin (1994) e Minayo (1999). Fizemos uma leitura detalhada e pormenorizada deste material, fazendo uma primeira classificação dando origem aos temas. A seguir, foi feito um refinamento e refeito o movimento classificatório, sendo que os temas foram agrupados pela convergência e relação de ideias, dando origem às categorias.

Neste processo, foram respeitados os princípios éticos e mantido o anonimato, conforme a Resolução 196/96. O estudo foi aprovado pelo comitê de ética Universidade Federal de Santa Catarina, sob o parecer 256/08. Foram resguardadas as identidades dos participantes do estudo.

\section{Resultados e Análise}

Até setembro de 2008, o projeto atendeu a 49 grupos com 902 gestantes e 526 acompanhantes, o que representa uma média de 10 acompanhantes por grupo. Vale lembrar que nos primeiros grupos era reduzido o número de acompanhantes. A cada encontro era notório o envolvimento do pai e/ou acompanhante na gestação, bem como a melhor compreensão deste período complexo e único na vida do casal. Alguns homens chegaram a pensar na formação de um grupo de pais, o que não se efetivou. Percebe-se, no entanto, que os dados levantados indicam um aumento gradativo do número de acompanhantes que participam do grupo, sendo representados na sua maioria pelo marido ou companheiro, seguido de mãe, sogra e amigas. Chamaram a atenção três gestantes que vieram acompanhadas de seus pais e irmãos e em torno de cinco que vieram acompanhadas de outros filhos. Semelhante situação se mostra na pesquisa de Brüggemann, Parpinelli e Osis (2005) que aponta como escolha mais frequente do acompanhante no parto, o pai do bebê (47,6\%), a mãe (29,5\%), seguida de familiar do sexo feminino (tia, sogra, cunhada, irmã). 
Desvelando os conteúdos analisados, emergiram as seguintes categorias e subcategorias: a) compreensão do processo de nascimento. Subcategorias: aprofundamento, reafirmação, repadronização, socialização e transformação dos saberes e experiências; expressão de sentimentos, medos e dúvidas; desmistificação de crenças e mitos relativos à gravidez, parto, pós-parto e cuidados com o bebê; b) ampliação da percepção social e humanitária; c) fortalecimento do relacionamento conjugal. Subcategoria: melhor compreensão das sensações femininas pelo companheiro; d) fortalecimento dos vínculos afetivos com o novo ser e início da formação da nova família; e) sedimentação e consolidação do papel de pai na comunidade. Subcategorias: Preparação para a paternidade, autoafirmação e aumento de confiança para assumir o protagonismo no processo de nascimento, emersão do senso da responsabilidade e conhecimento de seus direitos.

\section{Compreensão do Processo de Nascimento}

Os acompanhantes tiveram a oportunidade de compartilhar conhecimentos e experiências, vivenciar situações similares às suas, de poder expressar seus anseios, medos e dúvidas em relação ao processo de nascimento, desmistificando crenças que envolvem esta fase de transição de vida. A participação nesta atividade coletiva permitiu ampliar e transformar conhecimentos, rever e mudar condutas, bem como reafirmar comportamentos para melhor compreender o processo e transitar nele com maior tranquilidade e segurança. Ademais, estimulou o pai a dar suporte emocional à sua companheira.

Sartori e Van Der Sand (2004) afirmam que as pessoas envolvidas com o processo de gestar, ao participarem de grupos, minimizam ansiedades, fantasias e temores manifestos em relação ao processo de nascimento. O grupo, para Delfino et al. (2004), constitui-se num espaço para compartilhar experiências, sentimentos e afetos e socializar saberes científicos e populares. Tal ação contribui para compreensão de si e do mundo e para a busca de possibilidades - recursos para a saúde integral no âmbito individual e coletivo. Podemos evidenciar a definição destes autores, por meio das declarações feitas pelos integrantes do grupo:

“Uma oportunidade de aprender coisas novas e reafirmar outras. Acho também que o curso dá um pouco mais de tranquilidade, principalmente para os pais marinheiros de “primeira viagem”, como nós.” (Grupo 7).

“Significou muito. Desmistificou muitas situações que imaginava e orientou para uma gestação tranquila e um parto confiante.” (Grupo 44). 
“O maior significado foi o de socializar os saberes, as dúvidas, as angústias e por fim o prazer de ser pai e protegido.” (Grupo 24)

\section{Ampliação da Percepção Social e Humanitária}

Durante a realização dos encontros do grupo, há uma valorização dos pequenos gestos do cotidiano, do carinho, do ser humano, do amor, da vida, da solidariedade, do que é normal no ciclo do desenvolvimento humano, em especial, do parto normal e da importância de proteger e humanizar o nascer, a vida e o mundo. Ávila (1998) destaca que, ao longo da gestação, surgem sentimentos de realização, aventura, preenchimento, amor, surgindo o sentimento de responsabilidade consigo e com o outro. Gestos insignificantes no dia-a-dia, segundo Buscaglia (2002), podem nos trazer para mais perto de nós mesmos e, consequentemente, dos outros. A reflexão sobre a vida e adoção de pequenas ações para protegê-la nesta e em outras gerações evidenciaram-se em um dos relatos:

“Todos sabemos que a saúde do bebê depende muito da saúde da mãe. Devemos, durante o tempo da gestação e amamentação, cuidar com todo o amor desta saúde, com muito carinho, atenção, tranquilidade e alegria. Afinal de contas, passamos agora a ser responsáveis por uma vida em formação. O mundo deve ser encarado agora também como responsável pela vida equilibrada de nossos seres, agora dependentes. Agora me toca ainda mais esse senso de responsabilidade. Que mundo desejo para a minha filha? Sonho com um mundo de águas cristalinas, correndo por entre as pedras, pássaros cantando, céu claro, baleias nos oceanos com seus filhotes brincando como nós com o nosso filho. Peço a Deus esse dom. Que me mantenha forte e amoroso para manter todo esse equilíbrio em nosso planeta. Peço carinho mais atenção com as nossas futuras gerações. Podemos fazer qualquer coisa. Podemos começar agora a nos humanizar com tudo que nos cerca” (Grupo 25).

Morin (2001) lembra que todas as ações se interligam, constituem uma teia de relações e interlocuções que se influenciam mutuamente. Para ele, o ser humano deve assumir sua missão antropológica: trabalhar para "humanização" da humanidade; concomitantemente obedecer à vida e guiá-la; assumir o destino humano em suas contradições e plenitude; alcançar a unidade planetária na diversidade; respeitar o outro, ao mesmo tempo, na diferença e na sua identidade; participar ativamente nas decisões e planejamentos; regenerar o senso de solidariedade e de responsabilidade para com todos os seres humanos, outros seres e terra pátria, resgatando a consciência e a cidadania planetária.

\section{Fortalecimento do Relacionamento Conjugal}


As informações e a troca de saberes e experiências com os profissionais e outros casais no grupo de gestantes e/ou casais grávidos sobre as transformações psicológicas, físicas e sociais da gravidez, os desconfortos gravídicos, a relação conjugal na gravidez e no pós-parto e a formação da família favoreceram a melhor compreensão por parte das mulheres e dos homens das mudanças e sentimentos inerentes a esta fase da vida, contribuindo para o fortalecimento do casal e da relação do trinômio. Segundo Ávila (1998), ter idéia e informações de situações futuras da gestação ou/e de todas as etapas do processo de nascimento previne a instalação de ansiedades desnecessárias, provocadas pelo desconhecimento das situações próprias da gravidez, parto e puerpério, estimula o diálogo e traz bem-estar e tranquilidade ao casal grávido. Para Hoga (2007), a inclusão dos homens nos grupos de orientação pré-natal diminui a angústia oriunda da incompreensão sobre o que está acontecendo com a mulher e do que pode ser feito para ajudá-la, minimiza sentimentos de rejeição em relação à gravidez e evita conflitos entre os casais.

Para Cowan (1988), a transição para a parentalidade pode ser uma oportunidade para a maturação e crescimento individual e marital. Depende dos padrões de interação estabelecidos, tanto comportamentais quanto de comunicação. Este processo ocorre em relação aos aspectos conjugais e às novas funções parentais em construção.

O grupo de gestantes utiliza o diálogo, a troca de experiências e saberes como uma ferramenta para atenuar os possíveis conflitos conjugais e pessoais inerentes à transição para a parentalidade, facilitando o exercício da maternidade e, sobretudo da paternidade como percebemos nos discursos abaixo.

"Realmente, através deste trabalho, pude aprender melhor a compreender sobre as sensações femininas, auxiliando-a da melhor forma possível.” (Grupo 40).

"É muito importante essa interação, pois auxilia na harmonização do casal entre si e com o bebê” (Grupo 46).

"Importância muito relevante. Como o companheiro e pai do bebê, acho que a participação é primordial para o processo de nascimento da criança. Um momento tão especial para todos. Acho que, além disso, ocorre o fortalecimento da relação do casal” (Grupo 45).

\section{Fortalecendo os Vínculos Afetivos com o Novo Ser e Iniciando a Formação da Nova Família}

Ter um tempo para pensar na gravidez, conversar sobre a importância de interagir com o bebê, pensar nele, dialogar e tocá-lo; saber da importância de contar histórias, ouvir 
músicas suaves e proporcionar um ambiente propício para o trinômio e se curtir na gestação. Isto estimula a formação do apego e o vínculo mãe, pai e bebê, contribuído para a formação da nova Família.

A participação em grupos de gestante é essencial para o estabelecimento dos primeiros vínculos entre o pai e o bebê. Piccinini et al. (2004) revela que, de modo geral, os pais procuram algum meio de interagir com o bebê ainda durante a gestação. A percepção das manifestações do bebê gera grande emoção nos pais, pois isso os torna parte de suas vidas. Muitos pais manifestaram ter a impressão de que seu filho os reconhecia e respondia aos estímulos quando falavam ou tocavam na barriga de sua esposa e buscaram ativamente a interação com o bebê, desejando um contato mais próximo com ele, através de conversas, da leitura de histórias, de carícias e beijos na barriga da gestante. Esta disponibilidade para a interação com o bebê reflete uma vivência já bastante real da paternidade, além de um grande envolvimento emocional com o bebê. Nesta perspectiva, o grupo incentivou a interação e vínculo pai/mãe/bebê, e estimulou a participação do pai em todo o processo de nascimento.

“Além da aquisição de conhecimentos, um momento semanal fora do stress habitual para pensar e curtir a gravidez” (Grupo 14).

“Uma importante aproximação de nós, pais, com nossos bebês” (Grupo 30).

“O grupo de gestantes nos mostra o quanto é imprescindível o acompanhante durante todo o processo de nascimento, ajudando a mãe no trabalho de parto, dando-lhe maior segurança e tranquilidade. Além disso, é muito importante a presença do pai ou acompanhante no pós-parto, nos cuidados com o bebê. Depois que iniciamos o curso de gestante, o pai do meu filho ficou muito mais carinhoso e percebeu a sua importância em todo esse processo.” (Grupo 46).

A construção destes novos papéis de pai e de mãe caracteriza-se pela presença de crises, descobertas e aprendizagens, pela necessidade de adaptações e do estabelecimento de novas formas de interação na família (MINUCHIN, 1982).

“É muito importante essa interação, pois auxilia na harmonização do casal entre si e com o bebê (Grupo 46). Estar mais próximo do bebê e da mãe, aprendendo muitas coisas até então desconhecidas e descobrindo várias curiosidades” (Grupo 46).

\section{Sedimentação e Consolidação do Papel de Pai na Comunidade}

Os pais, ao refletirem sobre as experiências similares às suas, compreendem o processo de nascimento e as transformações pessoais, sociais e de papéis, expressam seus medos, sentimentos e dúvidas, conhecem seus direitos para que possam reivindicá-los junto à 
sociedade, trocam conhecimentos e experiências com outros casais. Dessa forma, os pais vão fortalecendo seus potenciais, aumentando sua segurança, confiança e passam a exercer com mais plenitude sua paternidade; propiciam mais segurança, suporte emocional e afetivo à sua companheira, assumindo o protagonismo de todo o processo.

A participação do homem no ciclo grávido puerperal e o surgimento deste novo pai vão além de assumir o compromisso social, incluem a relação e o compromisso afetivo e pessoal com seu filho e companheira.

De acordo com Sartori e Van Der Sand (2004), a participação em grupos das pessoas envolvidas com o processo de gestar tem se mostrado de grande valia. São terapêuticos e oferecem suporte às pessoas. Segundo Munari e Rodrigues (1997), o grupo pode ajudar pessoas durante períodos de ajustamentos a mudanças, no tratamento de crises ou ainda na manutenção ou adaptação a novas situações. Para Ávila (1998); Said (1995) e Zampieri (2007), a participação da gestante e dos familiares, sobretudo do pai, nas atividades educativas coletivas, amplia os conhecimentos e as possibilidades de as pessoas se autoconhecerem e trocarem conhecimentos e experiências com casais que vivem situações similares às suas. É fundamental para que as mulheres e seus companheiros fortaleçam seus potenciais, decidam, ajam e assumam os seus papéis de sujeitos no processo de gestar e parir. Ademais, oportuniza e auxilia as gestantes e os companheiros a esclarecerem dúvidas e enfrentarem as dificuldades interiores, preparando-os para a maternidade e paternidade e ajuda-os a quebrarem mitos que surgem durante a gravidez e o parto. Os discursos que seguem mostram que o grupo favorece a inclusão do pai no processo de nascimento.

"Hoje o acompanhante próprio se sente um intruso, inclusive pode acontecer na hora do parto. O grupo de gestantes quebra essa barreira e inclui o acompanhante e o "engravida”. Sai “a grávida” para “o casal grávido” (Grupo 46).

"Muito importante, pois é mais uma oportunidade de o nascimento ser um processo que não seja só da mulher, mas algo compartilhado com aquele que também participará dos outros momentos importantes para a criança que irá nascer” (Grupo 45).

Viçosa (1997) refere que nos grupos de gestantes se cria um espaço no qual os participantes podem expressar seus problemas e refletir sobre eles. Nesta perspectiva, há o incentivo para a troca de experiências, o que ajuda a atenuar os dilemas dessa etapa da vida e a compreensão da importância de cada protagonista desta história: “É um momento que o acompanhante sente-se mais próximo de aspectos concretos da gravidez, parto e pós-parto, que muitas vezes ele não se dá conta que estão acontecendo ou irão acontecer. É uma 
oportunidade para que ele possa adotar uma posição mais ativa neste cenário e passe a viver desde já a experiência de ser pai” (Grupo 46).

“Conhecer nossos direitos. Não ser apenas visita. Sentir-se integrante e importante nesse processo importante. Entender as situações vividas e as possíveis” (Grupo 46).

\section{Considerações Finais}

O grupo de gestantes e/ou casais grávidos estimula a participação do acompanhante, fortalece seus potenciais e conhecimentos para que possa auxiliar a gestante nas novas vivências. Além disso, divulga a importância do seu papel, informa sobre os seus direitos, auxilia na quebra de mitos e tabus relativos à gestação, parto e puerpério, socializa novos conhecimentos e experiências que favoreçam a compreensão desta nova etapa de vida e o relacionamento do casal. Também propicia espaços para expressar medos, dúvidas e sentimentos e contribui no preparo para a maternidade e paternidade, no caso do acompanhante ser o companheiro.

O grupo de gestantes e/ou casais grávidos do HU tem tido um papel relevante, constituindo-se em uma oportunidade para a inclusão do acompanhante no processo de nascimento e para o exercício e fortalecimento da paternidade. Tem estimulado o protagonismo do pai neste processo, e reforçado a importância de seu papel junto a sua companheira, dando a ela suporte emocional, segurança e tranquilidade.

O grupo procura divulgar e sedimentar a importância do acompanhante junto às unidades locais de saúde, instituições hospitalares e sociedade. Sobretudo, estabelece parcerias com acompanhantes, gestantes e familiares, para que possam intervir na realidade existente, propor e exigir mudanças, promovendo melhoria na qualidade da assistência prestada à mulher grávida.

Assim sendo, torna-se fundamental que esta prática seja divulgada e oferecida aos casais grávidos, e que os profissionais de saúde estimulem a participação das mulheres e companheiros precocemente.

\section{Referências}


ALONSO, I.; VERDI, M. In: VERDI, M., BOEHS, A. E., ZAMPIERI M. F. M.

Enfermagem na atenção primária de saúde. Textos Fundamentais, v. 1, Saúde Coletiva e Saúde da Criança. Florianópolis: Editora UFSC, 2005.

ALVES, V.S. Educação em saúde e constituição de sujeitos: desafios ao cuidado no Programa da Saúde da Família. Dissertação (Mestre em Saúde Coletiva). Programa de Pós Graduação em Saúde Coletiva do Instituto de Saúde Coletiva da Universidade Federal da Bahia, Salvador, 2004. 192 p

ANDREANI, G. Satisfação e responsabilidade: o envolvimento do pai na gravidez durante a transição para a parentalidade. Dissertação (Mestrado em Psicologia) - Universidade Federal Santa Catarina, Florianópolis, 2006.

ÁVILA A. A. Socorro, Doutor! Atrás da barriga tem gente! São Paulo: Ateneu, 1998. 215p.

BARDIN, L. Análise de Conteúdo. Lisboa: Edições 70, 1994. 227p.

BIASOLI-ALVES, Z. M. M. A Pesquisa psicológica: a análise de métodos e estratégias na construção de um conhecimento que se pretende científico. Diálogos Metodológicos sobre Prática de Pesquisa. Ribeirão Preto, 1998.

BRASIL. Ministério da Saúde. Lei No 11.108, de 7 de Abril de 2005. Garante à parturiente presença de acompanhante no âmbito do SUS. Poder Executivo, Brasília, DF, 2005 Disponível em <http://www.planalto.gov.br/CCIVIL/_Ato2004-2006/20 05/Lei/L11108.htm>Acesso em 12 mar. 2006.

BRASIL. Ministério da Saúde. Portaria n 1.067/GM de 4 de julho de 2005. Institui a Política nacional de Atenção Obstétrica e neonatal. Diário Oficial da União [da] República Federativa do Brasil n. ${ }^{\circ}$ 128, 6 jul. 2005. Poder Executivo, Brasília, DF, 2005b. Seção 1. Disponível em <http://dtr2001.saude.gov.br/sas/PORTARIAS/Port20 05/G M/GM-1067.htm $>$ Acesso em 12 mar. 2006.

BRAZELTON, T. B. O desenvolvimento do Apego: uma família em formação. Porto Alegre: Artes Médicas, 1988, 208 p.

BRÜGGEMANN, O. M; PARPINELLI, M. A; OSIS, M. J. D. Evidências sobre o suporte durante o trabalho de parto/parto: uma revisão da literatura. Cad. Saúde Pública, Rio de Janeiro, v. 21, n. 5, p. 1316-1327, set-out, 2005.

BUSCAGLIA, L. Amor. 22. ed. Rio de Janeiro: Nova era, 2002. 
COWAN, P. A. Becoming a father: a time of change, an opportunity for devolopent. In: BRONSTEIN, P.; COWAN, C. P. Fatherhood today: men's changing role in the family. New York: John Wiley \& Sons, 1988.

DELFINO, M. R; PATRÍCIO, Z. M.; MARTINS, A.S.; SILVÉRIO, M. R. S. O processo de cuidar participante com um grupo de gestantes: repercussões na saúde integral individualcoletiva, Ciênc. saúde coletiva, v.9, n. 4, Rio de Janeiro. Oct./Dec. 2004.

FREITAS, W. M. F.; COELHO; E. A. C. ; SILVA, A. T. M. C. Sentir-se pai: A vivência masculina sob o olhar de gênero. Cadernos de Saúde Pública, v.3, n.1, Rio de Janeiro, jan. 2007. Disponível em: <http://www.scielo.br/pdf/csp/v23n1/14.pdf>. Acesso em: 16 Abr. 2008.

HOGA, L. A. K. Perspectiva masculina da saúde da mulher. In: FERNANDES, R. A. Q; NARCHI, N. Z. (orgs.). Enfermagem e Saúde da Mulher. São Paulo: Manole, 2007. Cap.17, p. 288-307.

MALDONADO, M. T. P. Psicologia da Gravidez: Parto e Puérperio. Petrópolis: Vozes, 2005.

MALDONADO, M. T; DICKSTEIN, J. ; NAHOUM, J.C. Nós estamos grávidos. 11 ed. São Paulo: Saraiva, 2000

MENEZES, C. C.; LOPEZ, R. C. S. Relação conjugal na transição para a parentalidade: gestação até dezoito meses do bebê. Psico-USF, v. 12, n. 1, p. 83-93, jan./jun. 2007.

Disponível em: <http://pepsic.bvs-psi.org.br/pdf/psicousf/v12n1/v12n1a10.pdf> Acesso em: 08 maio 2008.

MINAYO, M. C. de S. O desafio do conhecimento: pesquisa qualitativa em saúde. 6. ed. São Paulo; Rio de Janeiro: Hucitec. 1999. 269p. ISBN 8527101815

MINUCHIN, S. Famílias: funcionamento e tratamento. Porto Alegre: Artes Médicas, 1982.

MORIN, E. Os sete saberes necessários à educação do futuro. São Paulo: Cortez, Brasília, DF: UNESCO, 2001. 118p.

MUNARI, B. D.; RODRIGUES, A. R. F. Enfermagem e grupos. Goiânia: AB, 1997. 
NORONHA, D. T.; LOPES, G. P.; MONTGOMERY, M. Tocoginecologia psicossomática. São Paulo: Almed, 1993. 233p.

OLIVEIRA, M. E.; ZAMPIERI, M. de F. M.; BRUGGEMANN, O. M. A melodia da Humanização: reflexões sobre o cuidado no processo de nascimento. Florianópolis: Cidade Futura, 2001. ISSN 85.87757

PARKE, R. S. Fatherhood. London: Harward University Press, 1996.

PERSEVAL, G. D. A parte do pai. Porto Alegre: L\&MP, 1986.

PICCININI, C. A. O Envolvimento Paterno durante a Gestação. Psicologia: Reflexão e Crítica, v.17, n. 3, 2004, p. 303-314.

RIOS, C.T.F; VIEIRA, N.F.C. Educational action in prenatal care: a reflection on nursing consultation as an opportunity for health education. Ciênc. saúde coletiva, Rio de Janeiro, v. 12, n. 2, 2007. Disponível em: <http://www.scielo.br/scielo.php?script= sciarttext\&pid=S1413-1232007000200024\&lng=en\&nrm=iso>. Acesso em: 17 ago. 2007.

SAID FA. No "ser com”, o cuidar pelo re-significar do cotidiano de um grupo de mulheres em gestação. Florianópolis, UFSC, 1995. Dissertação (Mestrado em Assistência de Enfermagem). Curso de Pós Graduação em Enfermagem, Universidade Federal de Santa Catarina, 1995.

SANTOS, O. M. B.; ZAMPIERI, M. de F. M.; CUSTÓDIO, Z. A. de O.; GULARTE, M. Projeto de extensão: grupo de gestantes ou casais grávidos, Florianópolis, 1996.

SARTORI, G. S.; VAN DER SAND, I. C. P. Grupo de gestantes: espaço de conhecimentos, de trocas e de vínculos entre os participantes. Revista Eletrônica de Enfermagem, v. 06, n. 2, p.153-165, 2004. Disponível em: www.fen.ufg.br. Acesso em mar. 2006.

TIBA, I. Quem ama educa. São Paulo: Editora Gente, 2002.

TRINDADE, Z. A. As representações sociais e o cotidiano: a questão da maternidade e da paternidade. Psicologia: teoria e pesquisa. Brasília, 1993.

VIÇOSA, G. R. Grupos com gestantes. In: ZIMERMAN, D. E.; OSÓRIO, L. C. Como Trabalhamos com Grupos. Porto Alegre: Artes Médicas, 1997. 
ZAMPIERI, M. F. M. Cuidado humanizado no pré-natal: um olhar para além das divergências e convergências. Florianópolis, UFSC, 2006. 437p. Tese (Doutorado em Enfermagem, área de concentração: Filosofia, Saúde e Sociedade). Programa de PósGraduação em Enfermagem, Universidade Federal de Santa Catarina, 2006b.

ZAMPIERI, M. F. M. Relatório do grupo de gestantes ou casais grávidos-2007, Florianópolis, 2007.

ZAMPIERI, M. F. M.; GARCIA, O. R. Z. G.; BOEHS, A.; E.; VERDI, M. Enfermagem na Atenção Primária à Saúde da mulher- Textos Fundamentais. Série atenção Primária de Saúde- v. 2. Florianópolis: UFSC/NFR, 2006a ISBN 85.88612-42 X. 